\title{
Exploration of Social Accountability Indicators in Medical Science Schools in Iran
}

\author{
Hajar Shieh, ${ }^{1}$ Shirin Ghanavati, ${ }^{1}$ Parisa Nabeiei, ${ }^{1}$ and Mitra Amini ${ }^{1,}{ }^{*}$ \\ ${ }^{1}$ Quality Improvement in Clinical Education Research Center, Education Development Center, Shiraz University of Medical Sciences, Shiraz, IR Iran \\ "Corresponding author: Mitra Amini, Quality Improvement in Clinical Education Research Center, Education Development Center, Shiraz University of Medical Sciences, \\ Shiraz, IR Iran. Tel: +98-7132333064, E-mail: mitraamini51@yahoo.com
}

Received 2015 January 9; Revised 2016 March 23; Accepted 2016 March 26.

\begin{abstract}
Introduction: Social accountability has received much research attention in recent decades. Social accountability has been identified as an important prerequisite in development; however different development targets each have a particular definition of social accountability. The aim of this study was to provide indicators for application in making assessments for the progress of medical science colleges and institutions towards social accountability.

Methods: This research was conducted as a qualitative study in 2015. The research aimed to explore indicators of social accountability in medical science training institutions using three rounds of the Delphi technique. A group of experts was gathered from among all regions of Iran. Prior to the first round of Delphi, some proposed measures were identified from a review of the related literature. In the first round, content validity ratio values were determined for each indicator and accountability assessment was the made by the group of experts. In the second round of Delphi, item-content validity index determinations were made according to relevance and clarity of the indicators. In the third final round, confirmation of indicators was made by the group of experts.

Results: The four main domains of organization and performance, educational activities, research activities and cooperation in health services in society and region, were confirmed using the Delphi method. Finally, 58 objective indicators were listed for these 4 domains.

Conclusions: Determination of national criteria for evaluating social accountability is a major step toward improving accountability in medical training institutions. Evaluations for medical training institutions based on criteria derived from this study were determined as efficient. But further research is needed on function of the mentioned criteria in relation to fulfilling the needs of society.
\end{abstract}

Keywords: Social Accountability, Medical Education, Schools, Indicator

\section{Introduction}

During the recent two decades, the concept of social accountability has had much research attention, particularly on performance related to meeting the goals of millennium development (1). Accountability is a complex system of social communication by which an individual or an organization has certain obligations (2). Although accountability is not a new concept, according to experts, the modern global situation and internal issues of countries serve to increase the need for ongoing accountability (3). Optimal and appropriate development requires social accountability related to context and goals (2). Determining social accountability indicators for medical training institutions applies the same method as other organizations (2). Medical, para-medical staff and institutes that educate them, share the primary objective of serving society's humanitarian needs (4). According to what has been mentioned, there has recently been a serious revision of medical education programs due to increased populations, changes in prevalence of diseases and social differ- ences between poor and rich people, globally (5). During recent years there has been a culture among medical training institutions that provides education for students who show commitment to what they do as well as good theoretical knowledge and practical skills (6). According to the revision in developing countries, social accountability is increasingly the topic for discussion and debate (5). A century after Flexner's report, a major challenge of the 21st century has been to develop commitment among medical training institutions to improve health services. A new organizational structure needs to be developed in order to rise to this challenge. This can be developed through new accreditation standards and mechanisms to improve and evaluate the capacity of an organization to provide more effective health services (7).

In a research conducted by Leinster (1990) to determine sublimation definition in medicine, it was determined that needs and preferences of consumers of healthcare services should be considered. It should also be acknowledged that equal services need to be provided to con- 
sumers of these services. Although social accountability is an exclusive concept, its definition can vary according to a situation (8).

Medical training institutions have several obligations such as training professional employers, guiding researchers and providing health care services. Accordingly, WHO (World health organization) has provided guidelines for social accountability for medical training institutions, these are as follows:

"Obligation to direct their education, research and service activities toward addressing the priority health concerns of community, region, and or nation they have mandate to serve" and health priority should be determined by the government, health care providers, health-treatment specialists and individuals in a society" (6). By doing this, a new definition of priority in medicine would be created with more value than previous models and evaluation methods (9).

So, the process of determining priorities can vary according to location. Medical schools have made major advances in social accountability and are seeking continuous corrections in order to fulfill society's requirements (6). Their goal is to contribute to a system of health care provision in which activities are in line with the needs of society, as well as local and international benefit (6). If social accountability is more than an ideal concept, it needs tools for making evaluations. Medical schools, where accepted social accountability principles are a major issue, have reported some progress in obtaining their objectives (6).

Evaluation of social accountability requires a measurement tool with continuum that enables consideration of health features and outcomes. These features and outcomes include individual and group features of graduates and health indicators for all members of a society. Nowadays, most evaluation tools focus on producing graduates with knowledge and skills. So there remains the need to develop tools to measure these features (10). All activities conducted to evaluate accountability state that collaboration with experts is necessary to avoid distortion and confusion in social accountability and to enhance the system's credibility. Delphi presents a method to obtain experts' opinions in a short period of time. In previous studies to determine indicators of different issues, the Delphi method has also been used to obtain experts' opinions (11-13).

Major principles of social accountability are well edited and revised over a period of more than a decade, however application in medical training institutions is inadequate to meet the demands (6). According to the importance of social accountability in society on the one hand and according to its aspects in medical training institutions on the other, this research was done to determine indicators to evaluate the progress rate of medical training institutions in their application of social accountability.

\section{Methods}

This study was done in 2015. A group of experts was selected from all over the country. 12 experts participated in each of the 3 rounds of Delphi. Indicators for selecting experts were sourced from related articles in reference journals and according to their professional experience. General items for selecting experts was availability of adequate and precise information about the mentioned concept, having a master's degree or higher in a field related to the issue and at least 10 years' experience in the field. Exclusion criteria included an unwillingness to co-operate in any step of the study.

This qualitative study was conducted in 2 steps including a review of the literature and 3 rounds of the Delphi study. The study was conducted according to the following steps:

1- Determination of Items from a reviewing references and researches: In the present study, 75 resources were used to gather a list of indicators for social accountability.

1) References were found through the Google scholar search engine and other search engines such as Proquest, Pubmed and Elsevier using a combination of key words such as "social accountability", "social accountability indicators" and "social accountability in medical educational institutions".

2) Accreditation standards of medical training institutions were assessed and items related to social accountability were extracted.

3) Existing models of social accountability, WHO statements and items of global consensus for social accountability in medical training institutions were assessed and items related to evaluation of social accountability were considered.

2- Delphi: In the first round of the Delphi method, experts were asked to evaluate the importance of each item from among a list of items. After that, experts evaluated social accountability of medical training institutions based on a 3-degree range of "not needed", "it is useful but not essential" and "essential". Scores were given in the range of $(-1)$ to (1). After gathering data, they were analyzed using SPSS version 14 . Content validity ratio was calculated using the following formula. In the mentioned formula "Ne" was considered equal to the number of experts who considered items necessary. "N" was considered equal to the number of all experts who evaluated an item as necessary (14). As Lawshe and Schipper calculated, when the number of experts was 12, a minimum CVR of 0.56 was required to retain an indicator in the final form of the instrument (14). In the first round, it was also asked from ex- 
perts to write down their recommendations for new items in each domain. In the second round, items of the previous round and new recommended items were resent to experts and the results were presented to them. Experts were asked to score items, according to the guidelines, for "clarity" and "relation". A score of 1 determined no clearance and relation and a score of 4 was for complete relation of the item with the subject as well as its clearance. There was also a space below each table for stating existing misunderstandings or corrections. Experts' opinions were collected through questions that included open and closed questions. In the second round of Delphi, the questionnaire and its scores were analyzed. In this step, experts were asked to reassess their answers and it was explained to them that they could expand on explanations given to their previous answers. They were also allowed to change a score given to any of the items.

$C V R=\frac{\left(N e-\frac{N}{2}\right)}{\frac{N}{2}}$

Results derived from assessing "relation" and "clarity" of each indicator with recommended issues is presented below:

In this step, content validity was calculated for each item using this formula.

The number of individuals who considered an item clear and related (scores of 3 and 4 ) was divided by all individuals that were given evaluations in clearance and relation of items. If the clearance and relation of any item was evaluated as more than 0.79 based on the mentioned formula, then that item was determined as suitable. If a score was between $70 \%-79 \%$, then it was corrected.

In the third round of Delphi, the last edition of the questionnaire was evaluated based on agreements determined in the first and second rounds. Experts were requested to send their supplemented opinions.

Methodological considerations: Delphi is a structured qualitative research applied to reveal experts' opinions and it can be an excellent example or role model for application to other medical institutions in Iran and elsewhere.

Regarding the limitations and weaknesses, performing three rounds of Delphi was a huge undertaking and the researchers were unable to design needs assessment prior to the beginning of the study. Although an opinions' survey is valuable, it has some limitations. For example, it is possible that we had some subjectivity in the results; however, the best possible experts were selected to participate in the study and an attempt was made to give appropriate feedback to the experts. Many other organizations in research focused on medical education also used Delphi to explore ideas; it has also been applied to produce instruments and evaluation tools.

\section{Results}

Demographic information of experts is shown in Table 1.

Table 1. Shows Demographic Information of Participating Experts in the Second Round of Delphi

\begin{tabular}{|c|c|}
\hline Variation & No. (\%) \\
\hline \multicolumn{2}{|l|}{ Age } \\
\hline $20-40$ & $5(41.3)$ \\
\hline $41-60$ & $5(41.3)$ \\
\hline$>60$ & $2(16.6)$ \\
\hline \multicolumn{2}{|l|}{ Gender } \\
\hline Female & $4(33.3)$ \\
\hline Male & $8(66.6)$ \\
\hline \multicolumn{2}{|c|}{ Experience of professional activity, $y$} \\
\hline$\leq 10$ & $2(16.6)$ \\
\hline $11-20$ & $3(25)$ \\
\hline $21-30$ & $6(50)$ \\
\hline$>30$ & $1(8.3)$ \\
\hline \multicolumn{2}{|l|}{ Scientific degree } \\
\hline Full professor & $4(33.2)$ \\
\hline Associated professor & $4(33.2)$ \\
\hline Assisted professor & $2(16.6)$ \\
\hline Instructor & $1(8.3)$ \\
\hline Non-faculty & $2(16.6)$ \\
\hline
\end{tabular}

After performing a review of the literature, 57 indicators in 4 main domains and 11 sub-categories were presented as "indicators for assessing social accountability in medical education colleges". Major domains and related sub-categories derived from the present study are listed in Table 2.

Content validity Ratio was calculated during the first round of Delphi, 55 indicators were confirmed and 3 new indicators were recommended by experts. Content validity ratios of new suggested indicators were also confirmed through the second round of Delphi. By calculating CVI (content validity index) for all indicators in the second round of Delphi, 9 indicators needed revision (CVI between 0.7 - 0.79) and the other indicators were confirmed. Content validity ratio score and content validity index evaluations were computed for each indicator through first and second rounds of Delphi, these are demonstrated in Table 3. 
Table 2. Main Domain Suggested for Assessing "Social Accountability" in Medical Training Institutions

\begin{tabular}{l|c}
\hline \multirow{2}{*}{ Domain Title } & Sub-Category Title \\
\hline \multirow{2}{*}{ Organization and performance } & Mission and aims \\
\cline { 2 - 2 } & Management \\
\cline { 2 - 2 } Educational activities & Standards and accreditation \\
\cline { 2 - 2 } & Student admission \\
\cline { 2 - 2 } & Pducation program \\
\cline { 2 - 2 } Research activities & Professional continuous education \\
\hline \multirow{2}{*}{$\begin{array}{l}\text { Cooperation in health services of } \\
\text { society and region }\end{array}$} & Research \\
\cline { 2 - 2 } & Health researchers education \\
\cline { 2 - 2 } &
\end{tabular}

\section{Discussion and Conclusions}

Hereby, 58 indicators in 4 main domains and 11 subcategories were extracted. Results derived from Delphi led to omission of 2 indicators, addition of 3 indicators and editing of some of the existing indicators.

Yamani et al. emphasized determinations and definitions of proper national indicators and proper instruments to measure social accountability in medical education (15). A review of related studies showed that results of this study were inline with those reported in Hamed et al. (2015). Although the results of the mentioned study overlapped with those of the present study, it had a different method of categorization (10 domains and 28 indicators) (16). Categorization of indicators in the present study, confirmed by experts, was in line with the method cited in Entezari et al. (17) and consistent with the ASPIRE model (4).

The first area for evaluation of social accountability in the present study was "mission and aims", and 3 indicators were confirmed in this domain. The indicator "social accountability indicator based on WHO definition was continuously mentioned in the statement and according to the opinion of the experts it was the most necessary indicator.

Searel also reported that attention to society's needs should be the goal of colleges and provide the basis of social accountability (18).

5 indicators were confirmed in the sub-category of management. Indicators that actively involved students and faculty members with health challenges, application, appointment and promotion based on professional competence and cultural accountability and equitable distribution of funds based on needs have been attributed the highest importance according to opinions of experts.

Hamed et al. reports that clear, respondent management and manager's evaluation based on social accountability should be included in social accountability principles of medical schools (16).

Burdick et al. reports that functional, enhancing and professors' educating systems based on social accountability and professionalism should be included as an investment in successful accountability programs (19).

6 indicators were confirmed in the domain of "standards and accreditation". In this area internal evaluation and accreditation programs were confirmed as reinforcement factors in respondent management. Abdullah reports the essential role of social accountability in accreditation of medical schools (1). Abdullah, in another study reports that evaluation standards function as a method to guide medical schools' function in order to match them with organizational function and evaluation period. Thus, it is necessary to provide instruments for evaluation and accreditation in the domain of social accountability (20). This issue is in line with indicators of the subcategory entitled "standards and accreditation" in the present study.

There were 16 indicators in the domain of "education program" and 2 indicators in the domain of "post-graduate education". The most important academic function was provision and reinforcement of scientific and practical skills of learners, "education program" so that domain was determined as the main indicator for accountability. This domain was the most important indicator in the present study, confirmed by experts.

9 indicators were determined by Nili et al. as "necessary indicators in respondent curriculum of governmental universities"; 8 of which were in line with the confirmed indicators of the present study. Editing and provision of "curriculum under the goal of fostering innovation" has not been mentioned as necessary confirmed indicator of the present study, and this is considered reasonable due to the nature of the domain of health science (3).

A medical training institution is recognized as a respondent medical school that is aware of its responsibilities. An educational program should be based on major health issues in society. Providing society-based education was determined as an important feature of respondent medical schools (21).

2 domains were identified in the domain of "research activities"; they were "research activities" and "education of health system researchers". Hennen reports that one feature of social accountability in higher education institutes is implementation of research programs in order to fulfill society's needs and to solve its problems (22). Lingard and Karle report that improving and developing research is a leading step towards accountability in terms of fulfilling 
the needs of society (23).

In the domain of service provision, there were two confirmed indicators; "corporation in health services" and "graduates". 4 indicators were confirmed in the first domain and 7 in the second domain. In the domain of provision of services to society, the most necessary indicator was confirmed as direct cooperation in medical schools. Hennen reports that in order to make progress in accountability health sciences' colleges should develop clinical services for all members of society. Students' residencies in cities and provision of health care services in suburban areas should also be considered (22).

The most necessary indicators in the area of "graduates" showed two indicators; "assessment of graduates' functions" and "distribution and impact of graduates on society". Scott reports that universities should train students who can provide services to society using their knowledge, skills and with a readiness to fulfill national and local obligations. In other words, this is a relation between experiences and learning outcomes of students and their careers and economic roles (24).

It is acknowledged that the primary goal of a medical school is to serve the needs and expectations of society. Accordingly, social accountability is understood as an integral aspect of a medical teaching institution at its foundation. Rather than being an ideal situation through which all society's needs and expectations are fulfilled, social accountability presents a path towards an ideal. The complex, system dependent and multi-dimensional concept of social accountability is based on consideration and use of local indicators. These local indicators were determined in this study. Although this determination is definitely a small step towards improving social accountability, these indicators must be tested and improved through an evaluation process in order to actually achieve excellent social accountability. In addition, more studies must be done on the actual practical aspects of these indicators in order to improve social accountability in medical training institutions.

\section{Supplementary Material}

Supplementary material(s) is available here.

\section{Acknowledgments}

This manuscript was extracted from the thesis of the first author (grant No 93-7054). The authors therefore thank the vice-chancellery of research and technology at Shiraz University of Medical Sciences, Shiraz, Iran, for the financial support. The authors are grateful to the college deans for their cooperation in this study.

\section{Footnotes}

Authors' Contribution: Mitra Amini and Hajar Shieh designed, developed the concept of the study and gathered $\&$ analyzed the data in collaboration with Parisa Nabeiei and Shirin Ghanavati. Translation of this manuscript done with Shirin Ghanavati. All authors contributed to critical revising and editing of the final version of the manuscript and approved it for submission.

Conflict of Interest: None declared.

\section{References}

1. Abdalla ME. Suggested New Standards to Measure Social Accountability of Medical Schools in the Accreditation Systems. JCase Stud Accredit Assess. 2014;3.

2. Ahmadi K. Evolution of organizational social accountability industrial management. J Azad Univ Sannandaj. 2011;18(4):97-116.

3. Nili M, Nasr M, Sharif M, Mohammadi MM. Requirement for accountability in higher education curricula and social consequences Case Study: State University of Esfahan. Appl Sociol. 2010;38(2):57-76.

4. International Recognition of Excellence in Education . An introduction to excellence in social accountability of medical schools UK: ASPIRE; 2013. Available from: www.amee.com.

5. Rezaeian M, Pocock L. Social accountability-a challenge for global medical schools. Middle East J Fam Med. 2011;7(10):16.

6. Boelen C, Heck JE. Defining and measuring the social accountability of medical schools. Switzerland: World Health Organization; 1995.

7. GCSA . Global Consensus for Social Accountability of Medical Schools of Medical Schools. Switzerland: World Health Organization; 2010.

8. Leinster S. Evaluation and assessment of social accountability in medical schools. Med Teach. 2011;33(8):673-6. doi: 10.3109/0142159X.2011.590253. [PubMed: 21774656].

9. Woollard B, Boelen C. Seeking impact of medical schools on health: meeting the challenges of social accountability. Med Educ. 2012;46(1):21-7. doi: 10.1111/j.1365-2923.2011.04081.x. [PubMed: 22150193].

10. Woollard RF. Caring for a common future: medical schools' social accountability. Med Educ. 2006;40(4):301-13. doi: 10.1111/j.13652929.2006.02416.x. [PubMed: 16573665].

11. Amini M, Kojuri J, Lotfi F, Karimian Z, Abadi AS. Research priorities in medical education in the Eastern Mediterranean Region. East Mediterr Health J. 2012;18(7):687-92. [PubMed: 22891514].

12. Enjoo SA, Amini M, Tabei SZ, Mahbudi A, Kavosi Z, Saber M. The main indicators for Iranian hospital ethical accreditation. J Adv Med Educ Prof. 2015;3(3):117-32. [PubMed: 26269789].

13. Nabeiei P, Amini M, Ghanavati S, Marhamati S. Research priorities in medical education at Shiraz University of Medical Sciences:categories and subcategories in the Iranian context. $J$ Adv Med Educ Prof. 2016;4(1):26-32. [PubMed: 26793723].

14. Zamanzadeh V, Rassouli M, Abbaszadeh A, Majd HA, Nikanfar A, Ghahramanian A. Details of content validity and objectifying it in instrument development. Nurs Pract Today. 2015;1(3):163-71.

15. Yamani NF, Mohammad A. Social accountability of curriculum in medical education: Obstacles and Solutions. Iran J Med Educ. 2014;13(12):1082-98.

16. Hamed HJ, Amini A, Alizadeh M. Developing Social Accountability Indicators at Medical Schools. Res Dev. 2015;4(1):71-6.

17. Entezari A, Momtazmanesh N, Khojasteh A, Einollahi B. Toward social accountability of medical education in Iran. Iran J Publ Health. 2009;38(Suppl 1):27-8. 
18. Searle J, McHarg J. Selection for medical school: just pick the right students and the rest is easy!. Med Educ. 2003;37(5):458-63.

19. Burdick W, Amaral E, Campos H, Norcini J. A model for linkage between health professions education and health: FAIMER international faculty development initiatives. Med Teach. 2011;33(8):632-7. doi: 10.3109/0142159X.2011.590250. [PubMed: 21774649].

20. Abdalla ME. Social Accountability of Medical Schools: Do Accreditation Standards Help Promote the Concept?.J Case Stud Accredit Assess. 2014;3(1).

21. Goldman J, Reeves S, Lauscher HN, Jarvis-Selinger S, Silver I. Integrat- ing social accountability into continuing education and professional development at medical schools: the case of an institutional collaborative project in Canada. J Interprofes Care. 2008;22(sup1):40-50.

22. Hennen B. Demonstrating social accountability in medical education. CMAJ. 1997;156(3):365-7. [PubMed: 9033418].

23. Lindgren $S$, Karle $H$. Social accountability of medical education aspects on global accreditation. Med Teach. 2011;33(8):667-72. doi: 10.3109/0142159X.2011.590246. [PubMed: 21774655].

24. Scott JC. The Mission of the University: Medieval to Postmodern Transformations.J High Educ. 2006;77(1):1-39. doi:10.1353/jhe.2006.0007. 
Table 3. Shows CVR and CVI of Accepted Indicators

\begin{tabular}{|c|c|c|c|c|}
\hline Domain & Sub-Category & Indicator Number & CVR & CVI \\
\hline \multirow{14}{*}{ Organization and performance } & \multirow{3}{*}{ Mission and aims } & 1 & 0.83 & 0.83 \\
\hline & & 2 & 0.66 & 0.83 \\
\hline & & 3 & 0.63 & 0.83 \\
\hline & \multirow{5}{*}{ Management } & 1 & 0.63 & 0.83 \\
\hline & & 2 & 0.63 & 0.7 \\
\hline & & 3 & 0.66 & 0.91 \\
\hline & & 4 & 0.66 & 0.83 \\
\hline & & 5 & 0.66 & 0.8 \\
\hline & \multirow{6}{*}{ Standards and accreditation } & 1 & 0.66 & 0.83 \\
\hline & & 2 & 0.83 & 1 \\
\hline & & 3 & 0.66 & 0.83 \\
\hline & & 4 & 0.66 & .088 \\
\hline & & 5 & 0.66 & 0.7 \\
\hline & & 6 & 0.63 & 0.8 \\
\hline \multirow{25}{*}{ Educational activity } & \multirow{6}{*}{ Student admission } & 1 & 0.83 & 0.8 \\
\hline & & 2 & 0.66 & 0.9 \\
\hline & & 3 & 0.63 & 0.77 \\
\hline & & 4 & 0.83 & 0.83 \\
\hline & & 5 & 0.66 & 1 \\
\hline & & 6 & 0.63 & 0.9 \\
\hline & \multirow{16}{*}{ Education program } & 1 & 0.63 & 1 \\
\hline & & 2 & 0.63 & 1 \\
\hline & & 3 & 0.63 & 0.75 \\
\hline & & 4 & 0.66 & 0.75 \\
\hline & & 5 & 0.66 & 1 \\
\hline & & 6 & 0.63 & 0.72 \\
\hline & & 7 & 0.63 & 0.83 \\
\hline & & 8 & 0.63 & 1 \\
\hline & & 9 & 0.83 & 0.81 \\
\hline & & 10 & 0.63 & 0.8 \\
\hline & & 11 & 0.83 & 1 \\
\hline & & 12 & 0.66 & 1 \\
\hline & & 13 & 0.83 & 0.83 \\
\hline & & 14 & 0.63 & 0.81 \\
\hline & & 15 & 0.63 & 0.7 \\
\hline & & 16 & 0.63 & 0.75 \\
\hline & \multirow{2}{*}{ Postgraduate education } & 1 & 0.83 & 1 \\
\hline & & 2 & 0.66 & 1 \\
\hline & & 1 & 0.83 & 0.91 \\
\hline
\end{tabular}

Professional education 


\begin{tabular}{|c|c|c|c|c|}
\hline & & 2 & 0.63 & 0.9 \\
\hline & & 3 & 0.63 & 0.83 \\
\hline & & 4 & 0.63 & 1 \\
\hline \multirow{5}{*}{ Research activities } & \multirow{4}{*}{ Research } & 1 & 0.83 & 0.83 \\
\hline & & 2 & 0.63 & 1 \\
\hline & & 3 & 0.63 & 0.8 \\
\hline & & 4 & 0.66 & 0.9 \\
\hline & Health researchers education & 1 & 0.63 & 0.85 \\
\hline \multirow{11}{*}{ Cooperation in health services of society and region } & \multirow{4}{*}{ Health services cooperation } & 1 & 0.66 & 0.9 \\
\hline & & 2 & 0.66 & 0.75 \\
\hline & & 3 & 0.66 & 0.83 \\
\hline & & 4 & 0.66 & 0.91 \\
\hline & \multirow{7}{*}{ Graduates } & 1 & 0.66 & 1 \\
\hline & & 2 & 0.66 & 0.88 \\
\hline & & 3 & 0.63 & 1 \\
\hline & & 4 & 0.63 & 0.88 \\
\hline & & 5 & 0.66 & 0.9 \\
\hline & & 6 & 0.63 & 1 \\
\hline & & 7 & 0.63 & 0.9 \\
\hline
\end{tabular}

